\title{
Isolation and Anti-Leukemic Characterization of Extracellular L-asparaginase From Endophytic Bacterium, Brevibacterium sp. M-R21 Isolated Glycyrrhiza glabra Root
}

\author{
Hamed Esmaeil Lashgarian 1(D), Maryam Karkhane 1,2 (D), Seyedeh Zahra Mirzaei ${ }^{\text {(D) }}$, Abdolrazagh \\ Marzban 2,*(iD) \\ 1 Department of Medical Biotechnology, School of Medicine, Lorestan University of Medical Sciences, Khorramabad, Iran; \\ hamedesmaiili@gmail.com (H.E.L.); maryam_karkhane@hotmail.com (M.K.); \\ 2 Razi Herbal Medicines Research Center, Lorestan University of Medical Sciences, Khorramabad, Iran; \\ zahramirzaei1.1990@gmail.com (S.Z.M.); marzban86@gmail.com (A.M.); \\ * Correspondence: marzban86@gmail.com;
}

Received: 2.08.2020; Revised: 28.08.2020; Accepted: 30.08.2020; Published: 1.09.2020

Abstract: L-Asparaginase (L-ASPase) is known as a potent anti-cancer drug against L-Asparagineauxotroph tumor cells. In this study, an endophytic L-ASPase producing bacterium of the genus Bervibacillus from the root of Glycyrrhiza glabra was screened and characterized. After purification of the enzyme by ammonium sulfate precipitation, dialysis, and silica gel column chromatography, anti-cancer studies were performed against MRC-5 (normal lung cells) and U937 cell (leukemia cell line). Additionally, optimization fermentation was performed in terms of significant variables screened from a one-factor-at-the-time (OFAT) approach. The interactions of different experimental parameters were investigated using the response surface methodology (RSM) with the central composite design (CCD) algorithm. Cytotoxicity study showed that the dose-dependent effect of the L-ASPase at $100 \mathrm{IU} / \mathrm{ml}$ had a lethality of about $80 \%$ against leukemia cells. Therefore, the $\mathrm{IC}_{50}$ of the enzyme for leukemia cells was calculated to be approximately $33.54 \mathrm{IU} / \mathrm{ml}$. Interestingly, the cytotoxicity of L-ASPase against normal lung cells was only about 20\% at L-ASPase activity of 60-100 $\mathrm{IU} / \mathrm{ml}$. Based on the quadratic model, the optimal fermentation conditions were predicted to be $2 \%$ glucose, $2 \% \mathrm{NaCl}, \mathrm{pH} 7$, and incubation temperature $30^{\circ} \mathrm{C}$. Under these conditions, the highest enzyme activity was $90 \mathrm{IU} / \mathrm{ml}$, which had an efficiency of about $30 \%$ compared to non-optimized conditions. The results showed that L-ASPase isolated from Brevibacterium sp. M-R21 with selective cytotoxicity against the leukemia cell line may be a potential candidate as an anti-cancer drug after further study.

Keywords: L-Asparaginase; Anti-Leukemia activity; Brevibacterium sp. M-R21; Response Surface Methodology (RSM).

(C) 2020 by the authors. This article is an open-access article distributed under the terms and conditions of the Creative Commons Attribution (CC BY) license (https://creativecommons.org/licenses/by/4.0/).

\section{Introduction}

L-ASPase is one of the approved drugs for the treatment of soft tissue cancers such as lymphomas and leukemias. In addition, it has been shown that this enzyme can effectively stop the growth of some tumors, especially liver carcinoma (HepG2) and colon cancer (Hct-116) $[1,2]$. In fact, L-ASPase belongs to the group of amidohydrolase enzymes (E.C.3.5.1.1), catalyzing L-Asn to aspartic acid and ammonia. L-ASPase is found in all living organisms, 
including animals, plants, and microorganisms. In general, two types of L-ASPase have been identified in living organisms, including cytoplasmic L-ASPase or type I and secretory ones or type II. L-ASPase type I can catalyze L-glutamine in addition to L-Asn, while extracellular LASPase or type II intends a high affinity for L-Asn other than L-glutamine with a more specific catalytic activity $[3,4]$.

Some cancer cells have lost the ability of L-Asn biosynthesis due to mutations in the LASPase synthase gene. Therefore, L-Asn present in the bloodstream is required to proliferate and expand the tumor. The pharmacodynamic of L-ASPase is such that the enzyme triggers tumor death by depriving tumor cells of access towards extracellular asparagine [5-7]. Currently, two bacterial L-ASpases obtained from E. coli and Erwinia are used in combination with chemotherapy to treat acute lymphocytic leukemia (ALL) and lymphosarcoma [8,9]. However, commercially available L-ASpases have impediments due to their cross interactions, immune system stimulation, drug resistance, and nonspecific L-glutaminase activity [10]. Therefore, side effects associated with L-ASPase can lead to widespread liver dysfunction, pancreatitis, leukopenia, diabetes, neurological seizures, and coagulation abnormalities, and intracranial thrombosis [11]. Therefore, it seems reasonable why researchers are trying to find new L-ASPase with more desirable properties and minimal side effects [12]. Various reports have shown that bacterial-derived L-ASPases have more effective anti-leukemic properties and fewer side effects than other isoenzymes [13]. Endophytes are microorganisms that coexist with plants, and, to date, various metabolites have been isolated from them [14]. In this study, licorice endophytes were isolated from the plant root, and their ability to produce the L-ASPase was investigated. Licorice is one of the well-known plants that is widely used in traditional medicine. The medicinal properties of licorice are attributed to its root extract $[15,16]$. Besides, the licorice root is enriched with amino acids such that it could be a rational option for inhabiting endophytes that consume L-Asn as a source of carbon and nitrogen $[17,18]$. With this assumption, licorice was selected to maximize the chance of isolating L-ASPase producing endophytes, because L-ASPase-positive bacteria are far more likely to be found in places where the amino acid asparagine is abundant.

\section{Materials and Methods}

\subsection{Media and chemicals.}

Phenol red was purchased from Sigma; agar was purchased from Merck; other materials were of laboratory grade as obtained. The M9 basal salt medium used for L-ASPnase production included the following (for $100 \mathrm{ml}$ ): Glucose $1 \mathrm{~g}$; L-Asn $0.1 \mathrm{~g}$; $\mathrm{K}_{2} \mathrm{HPO}_{4}, 0.05 \mathrm{~g}$; $0.001 \mathrm{~g}, \mathrm{FeSO}_{4} ; \mathrm{CaCl}_{2} .2 \mathrm{H}_{2} \mathrm{O} .7 \mathrm{H}_{2} \mathrm{O}, 0.001 \mathrm{~g}$. For preparing $\mathrm{M} 9$ agar, $1.5 \mathrm{~g}$ of agar was added to M9 basal ingredients.

\subsection{Plant collection.}

The medicinal plant, Glycyrrhiza glabra (licorice), was collected Central District,

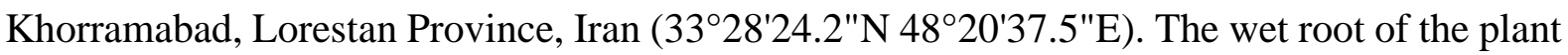
was collected in the plastic bags and transferred to the laboratory. 


\subsection{Bacterial isolation.}

The endophytic bacteria were isolated from the Glycyrrhiza glabra root, as described previously [19]. Briefly, the roots were sterilized by $75 \%$ (v/v) ethanol for 5 min and sodium hypochlorite $0.1 \%$ for $30 \mathrm{sec}$. After that, the roots were ground in the mortar, suspended on the sterile water. The suspension was serially diluted to $10^{-3}$, and $100 \mu \mathrm{l}$ were spread on the Muller Hinton agar (MHA) plates. The plates were incubated at $37{ }^{\circ} \mathrm{C}$ for $48 \mathrm{~h}$.

\subsection{Screening of asparaginase producing bacteria.}

L-ASPnase producing colonies were identified by colony spotting method on the surface of the M9 agar medium supplemented with $0.01 \mathrm{~g} / \mathrm{l}$ phenol red as a $\mathrm{pH}$ indicator. After $48 \mathrm{~h}$ incubation, the L-ASPnase-positive colonies were isolated based on creating a pink zone due to ammonia production in the agar medium with a yellow background. To confirm LASPnase activity, the isolate was cultured in M9 broth medium. After $48 \mathrm{~h}$, the culture medium was turned from yellow to pink color [4].

\subsection{Identification of asparaginase producing bacterium.}

Primary identification was performed using biochemical studies. In addition, $16 \mathrm{~S}$ rDNA gene sequencing was conducted to determine phylogenetic relationships. For this purpose, the first genomic DNA was extracted by DNA extraction kit (Qiagen, Germany). Then, 16S rDNA gene was amplified by PCR with one pair of primers, including forwarding (5-AGAGTTTGATCCTGGCTCAG-3) and Revers (5-AGGAGGTGATCCAGCC-3). The PCR reaction kit contained a master mix and loading dye from Wizol Company (South Korea). DNA amplification was performed as follows: initial denaturation at $94{ }^{\circ} \mathrm{C}$ for 5 min followed by 30 cycles of denaturation at $95^{\circ} \mathrm{C}$ for $1 \mathrm{~min}$, annealing at $55^{\circ} \mathrm{C}$ for $45 \mathrm{~s}$, extension at $72{ }^{\circ} \mathrm{C}$ for $1 \mathrm{~min}$, and a final extension at $72{ }^{\circ} \mathrm{C}$ for $5 \mathrm{~min}$ [20]. After that, the PCR product was electrophorized on $1 \%$ agarose and stained by safe stain (Sinaclon Co., Iran). The purified PCR product of the 16S rRNA gene was sequenced based on the Sanger method by Sinagene Company (Tehran, Iran). Nucleotide sequences were reviewed and edited by BioEdit software version 7.0.5 and BLASTed by blastn software in the NCBI Genbank website (http://blast. ncbi.nlm.nih.gov/BLAST.cgi). After identifying the bacterium, its $16 \mathrm{~S}$ rDNA fragment sequence was submitted to NCBI for assigning an accession number.

\subsection{L-ASPnase assay in broth medium.}

L-ASPnase activity was studied by the Nessler method in the bacterial culture medium. For this, the bacterium was cultured in a $250 \mathrm{ml}$ flask containing $100 \mathrm{ml}$ of M9 liquid medium and incubated in a shaker at $100 \mathrm{rpm}$ at $37{ }^{\circ} \mathrm{C}$ for $48 \mathrm{~h}$. The bacterial cells were then centrifuged at $25,200 \times \mathrm{g}$ for $15 \mathrm{~min}$, and the supernatant was taken to evaluate L-ASPnase activity. Briefly, $1 \mathrm{ml}$ of supernatant was added to $2.0 \mathrm{ml}$ of sodium borate buffer $(0.1 \mathrm{M}, \mathrm{pH} 8.5)$ in a glass tube. Then, $1 \mathrm{ml}$ of L-Asn solution $(0.05 \mathrm{M})$ was added to the tube. The reaction tube was incubated at $15{ }^{\circ} \mathrm{C}$ for $15 \mathrm{~min}$, and then the reaction was stopped with $0.5 \mathrm{ml}$ of trichloroacetic acid (TCA, 15\%). The reaction tube was centrifuged at 11,200 $\times \mathrm{g}$ for $15 \mathrm{~min}$ to precipitate the inactivated enzyme. Finally, the solution absorbance was measured at $450 \mathrm{~nm}$, and the LASPnase activity was calculated using the equation obtained from the standard curve [21]. 


\subsection{Enzyme extraction and purification.}

The 48-h cultured broth medium was centrifuged at $8000 \mathrm{~g}$ for 15 minutes at $4{ }^{\circ} \mathrm{C}$ to precipitate bacterial cells. The supernatant containing crude enzyme was taken for subsequent purification steps. A volume of $100 \mathrm{ml}$ of CFS was mixed with an equal volume of $70 \%$ ammonium sulfate solution and kept in an ice bath for 30 minutes. After that, the mixture was centrifuged at $4500 \mathrm{~g}$ for 15 minutes. The precipitate was then dissolved in phosphate buffer (PBS) (0.1 M, pH 7) and dialyzed against the increased volume of PBS (0.01 M). The dialysate was subjected to a Sephadex G-100 column $(920 \times 1.25 \mathrm{~cm})$. Briefly, $10 \mathrm{ml}$ of dialysate was loaded over the column and eluted with $0.1 \mathrm{M}$ Tris-HCl buffer ( $\mathrm{pH} 8$ ) so that 20 fractions were collected per $10 \mathrm{~min}$. Subsequently, the resulting fractions were examined for L-ASPnase activity and protein assays. The amount of total protein at each stage of purification was measured using the Bradford method from a standard curve constructed by bovine serum albumin (BSA) [21, 22]. The enzyme unit (U) for L-ASPnase expresses the amount of enzyme which releases $1 \mathrm{~mol}$ of ammonia per min. The specific activity is defined as the number of enzyme units per milligram of protein.

\subsection{Antileukemia activity assay.}

The anti-tumor activity of the purified L-ASPnase enzyme was investigated on MRC5 (normal lung cells) and U937 cell (leukemia cell line) [10]. The $\mathrm{IC}_{50}$ was determined by treating different concentrations of the enzyme on the cell lines and measuring their survival by MTT method [10]. Briefly, a number of $10^{4}$ cells with $80 \%$ confluency were seeded in 96well-plate containing $150 \mu$ RPMI-1640 medium supplemented with $10 \%$ fetal bovine serum (FBS). A volume of $50 \mu \mathrm{l}$ containing different concentrations of L-ASPnase was added to each well. The plate was incubated at $37{ }^{\circ} \mathrm{C}$ in a $\mathrm{CO}_{2}$ incubator for $48 \mathrm{~h}$. After that, $10 \mu \mathrm{lof}$ MTT reagent was added in each well, and the plates were incubated again for $4 \mathrm{~h}$ under the same conditions. The produced formazan crystals were precipitated by centrifugation at $250 \times \mathrm{g}$. After removing the supernatant, the formazan blue crystals were dissolved with $150 \mu \mathrm{l}$ of DMSO. The absorbance of the formazan solution was measured at $570 \mathrm{~nm}$ by a microplate reader [21]. The viability of treated cells was calculated by the following equation:

$$
\text { Viability }(\%)=\frac{\text { Treated sample absorbance }}{\text { Control sample absorbance }} \times 100
$$

\subsection{Optimization of L-ASPnase production.}

2.9.1. Preliminary screening of effective factors.

Factors affecting the L-ASPnase production by the bacterium were determined based on one-factor-at-the-time (OFAT) under submerged fermentation. Preliminary studies without considering the interaction of various factors such as incubation time (12, 24, 48 and $72 \mathrm{~h}$ ) temperature $\left(20,25,30,35\right.$ and $\left.40{ }^{\circ} \mathrm{C}\right), \mathrm{pH}(5,6,7,8$ and 9$)$ and salinity $(0,1,3$ and 5\%) as well as nitrogen $(0.1,0.25,0.5$ and $1 \mathrm{mg} / \mathrm{l})$ and carbon (glucose) $(0.5,1$, and $3 \%)$ sources on L-ASPnase activity were investigated. All experiments were performed in triplicate. 


\subsubsection{Response surface method optimization.}

The variables with the greatest impact on L-ASPnase activity extracted from the primary optimization method were selected for experimental design. These variables included initial $\mathrm{pH}(4-10)$, temperature $\left(25-35^{\circ} \mathrm{C}\right), \mathrm{NaCl}(1-3 \%)$ and glucose $(1-3 \%)$. Statistical optimization was designed based on response surface methodology with the central compound design algorithm (CCD). Based on the experimental pattern, 30 total runs included 6 center points, 8 axial points, and 24 factorial points (Table 3). The axial points were considered as rotatable points, which confirm any curvature in the response. Analysis of variances (annotated ANOVA) was conducted to analyze the statistical significance of the model, and each term $[21,22]$. A second-order polynomial model was predicted from RSM demonstrating linear, quadratic, and interaction effects of variables on the response (L-Asp activity) as follows:

$$
\mathrm{Y}=\beta_{0}+\sum_{i} \beta_{\mathrm{i}} \mathrm{x}_{\mathrm{i}}+\sum_{\mathrm{ii}} \beta_{\mathrm{ii}} \mathrm{x}_{\mathrm{i}}^{2}+\sum_{\mathrm{ij}} \beta_{\mathrm{ij}} \mathrm{x}_{\mathrm{i}} \mathrm{x}_{\mathrm{j}}
$$

Where $\mathrm{Y}$ is the predicted response (L-ASPnase activity) around the variable levels of $\mathrm{Xi}$ and $\mathrm{Xj}$, other terms including $\beta 0, \beta \mathrm{i}, \beta \mathrm{ii}$, and $\beta \mathrm{ij}$ represent the constant coefficients of intercept, linear, squared, and interaction effects, respectively. $\beta_{0}$ is the constant coefficients of intercept; $\beta_{\mathrm{i}}, \beta_{\mathrm{ii}}$ and $\beta_{\mathrm{ij}}$ represent coefficients of the linear, quadratic and interactive terms, respectively.

\section{Results and Discussion}

\subsection{Isolation and identification of L-ASPnase producing bacterium.}

Forty-five different endophytic strains were examined for L-ASPnase production using a modified M9 broth medium (Figure 1). Here, an isolate with the highest L-ASPnase activity was selected for further studies.

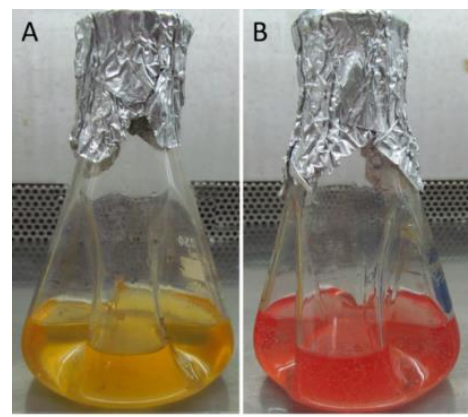

Figure 1. M9 broth medium. A) Before the cultivation of L-ASpase producing bacterium and B) After production of L-ASpase by the bacterium in 24-h incubation.

\subsection{Bacterium characterization.}

According to genetic alignment, approximately $99 \%$ of the sequence similarity between the isolated bacterium and other Brevibacterium species was established. Figure 2 shows the isolated phylogenetic relationship with different species of Brevibacterium. As can be seen, according to the similarities percent of the bacterium with the Brevibacterium genus, the associated 16S rRNA gene was deposited in the NCBI GeneBank called Brevibacterium MR21 with the accession number MT749247. 


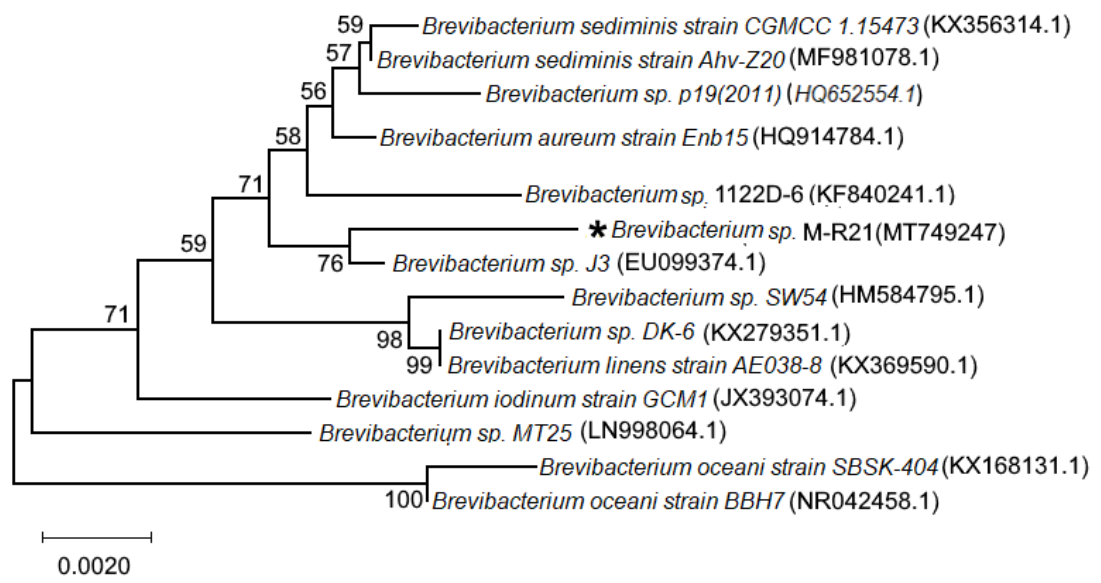

Figure 2. Phylogenetic tree displays neighboring relations between Brevibacterium M-R21with the closest $16 \mathrm{~S}$ rRNA gene sequences retrieved from NCBI. The isolated bacterium was labeled as a black star. The bootstrapping value was generated from 1000 replicates, which are presented as branch distance from the clades.

Brevibacterium is a gram-positive bacterium inhabiting soil belonging to the Actinomycetales family. The closest genus to Brevibacterium is Corynebacterium, from which various metabolites are obtained. Brevibacterium flavum, for example, now classified as Corynebacterium glutamicum, is one of the most applicable organisms for producing glutamic acid and lysine [23]. Although several metabolites, particularly various enzymes, have been isolated from other actinomycetes, this study is the first report of L-ASPnase activity of a bacterium of the Brevibacterium genus.

\subsection{L-ASPnase extraction and purification.}

The extracellular enzyme secreted by the bacterium in the M9 broth medium was purified by steps including ammonium sulfate precipitation, dialysis, and gel filtration column chromatography onto Sephadex G-100 (Sigma, USA). The crude enzyme indicated a specific activity of $0.14 \mathrm{IU} / \mathrm{mg}$, while after precipitating by ammonium sulfate, enzyme activity reached $0.36 \mathrm{IU} / \mathrm{mg}$. With the desalination of the resultant by dialysis, enzyme activity increased 0.52 $\mathrm{IU} / \mathrm{mg}$, and ultimately purified enzyme was obtained by column chromatography showing 0.67 $\mathrm{IU} / \mathrm{mg}$ specific activity (Table 1). As seen in Table 1, the enzyme activity with increasing purity arose about 4.7 folds compared to the crude enzyme.

Table 1. Purification process of L-ASPase from M9 broth and yield of each step.

\begin{tabular}{l|l|l|l|l}
\multicolumn{1}{c|}{ Step } & \multicolumn{1}{|c|}{ Volume(m) } & $\begin{array}{c}\text { Total } \\
\text { protein(mg/ml) }\end{array}$ & Activity(IU/ml) & $\begin{array}{c}\text { Specific } \\
\text { activity(IU/mg) }\end{array}$ \\
\hline Crude extract & 100 & 0.53 & 0.051 & 0.14 \\
\hline $\begin{array}{l}\text { Ammonium sulfate } \\
\text { precipitation }\end{array}$ & 56 & 0.44 & 0.44 & 0.36 \\
\hline Dialysis & 6.5 & 0.32 & 0.32 & 0.52 \\
\hline Chromatography & 1.5 & 0.17 & 0.18 & 0.67
\end{tabular}

\subsection{Purification assay of L-Asp enzyme.}

The purified enzyme was subjected to SDS-PAGE for determining its molecular weight. As seen in Figure 3, the molecular weight of the purified enzyme was estimated at 43 $\mathrm{kDa}$. Based on the other studies, most L-ASPnase isolated from gram-positive bacteria, especially the Bacillus genus, had molecular weight within 35-47 kDa [24-27]. For instance, Roy et al. (2018) isolated an L-ASPnase enzyme from B. megaterium with a molecular weight 
of $47 \mathrm{kDa}$ on SDS-PAGE [28]. Sudhir et al. (2016) purified an L-ASPnase from $B$. licheniformis with $37 \mathrm{kDa}$ showing a potent antineoplastic activity [24]. Zhang et al., 2015 cloned a new L-ASPnase from B. megaterium in $E$. coli that its molecular weight was 39.63 $\mathrm{kDa}$ [25]. Our study showed that L-ASPnase obtained from Brevibacterium is probably similar to those enzymes isolated from Bacillus species.

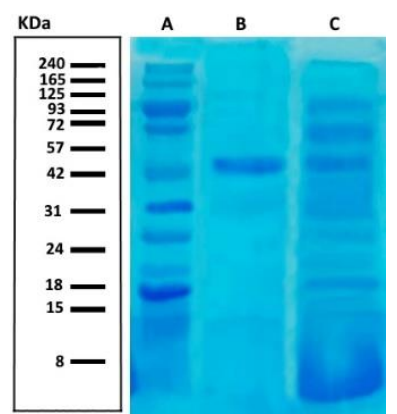

Figure 3. SDS-PAGE of purified L-ASPase. Lane A shows protein weight Marker, Lan B displays purified LAsp enzyme from G-100 column, and Lane C- crude enzyme (unpurified).

\subsection{Anti-cancer activity of L-ASPnase.}

The cytotoxicity of L-ASPase isolated from microorganisms and plants against a wide range of cell lines has been confirmed in numerous studies [1, 13, 27]. In 2018, Moharib examined the effect of a plant-derived L-ASPase isoenzyme on leukemia and Hela cells. They concluded that the inhibitory effect of the enzyme on HepG2 was significantly greater than Hela cells [29]. Numerous studies have shown that L-ASPase derived from microbial sources, unlike plants, exert more toxicity effect on the cells [13]. One study reported the toxicity effect of L-ASPase isolated from Aspergillus oryzaei against Hela cells [30]. Another similar study showed that an L-ASPase from Aspergillus flavus inhibited only 50\% of leukemia cells [31]. In this study, L-ASPase isolated from Brevibacterium could inhibit the growth of the leukemia cell line (U937) in dose-dependent mode (Figure 4). In addition, the toxicity effect of the LASPase was significantly increased against the normal cell line (MRC-5).

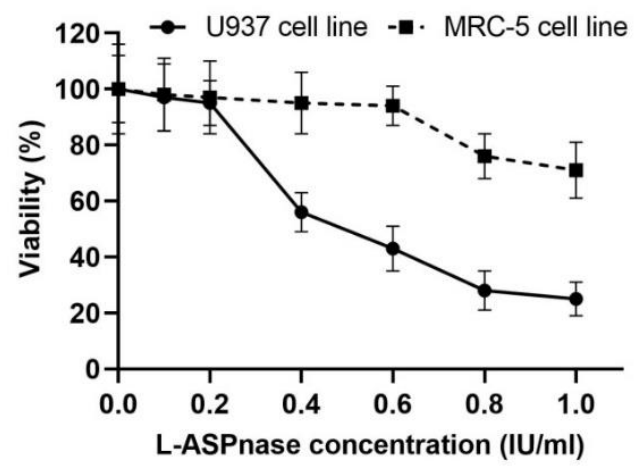

Figure 4. Cytoxicity of purified L-ASPase from Brevibacterium M-R21 against U937 and MRC-5 cell lines.

Therefore, our study showed that L-ASPase from Brevibacterium exerts a selective inhibition against the different cell lines. Studies have shown that high enzyme activity does not mean that the enzyme is suitable for pharmaceutical use. The stability of L-Asp activity under physiological conditions such as $\mathrm{pH}$ and osmolarity are the main criteria in selecting the enzyme as an anti-leukemia drug [3, 13, 32]. Therefore, the most significant analysis is to determine the anti-cancer activity of the enzyme in the tumor cells in vivo. However, the 
findings of this analysis indicate that the enzyme produced by Brevibacterium sp. M-R21 has relatively appropriate properties, although more thorough and in-depth studies are required.

\subsection{OFAT experiment.}

OFAT optimization method was used to screen for significant variables on bacterial LASPase activity. Figure 5 shows the results of 6 different variables on L-ASPase activity. Of these parameters, four were selected with the most significant effect for statistical analysis of surface response. Therefore, the OFAT method is first used to investigate the effect of various factors on microorganisms. In this method, the interaction of factors is not considered, and only evaluates one case at a certain time without considering others [33]. In this study, the factors affecting L-ASPase activity included $\mathrm{pH}$, temperature, $\mathrm{NaCl}$, and glucose (as a carbon source). Examining the effect of carbon and nitrogen source, it was found that $3 \%$ glucose concentration could increase L-ASPase activity, while nitrogen (ammonium chloride) concentration had no effect on L-ASPase activity. Studies have shown that glucose in culture media increases enzymatic activity. Besides, to economically produce L-ASPase, glucose is preferred over other carbon sources [34].
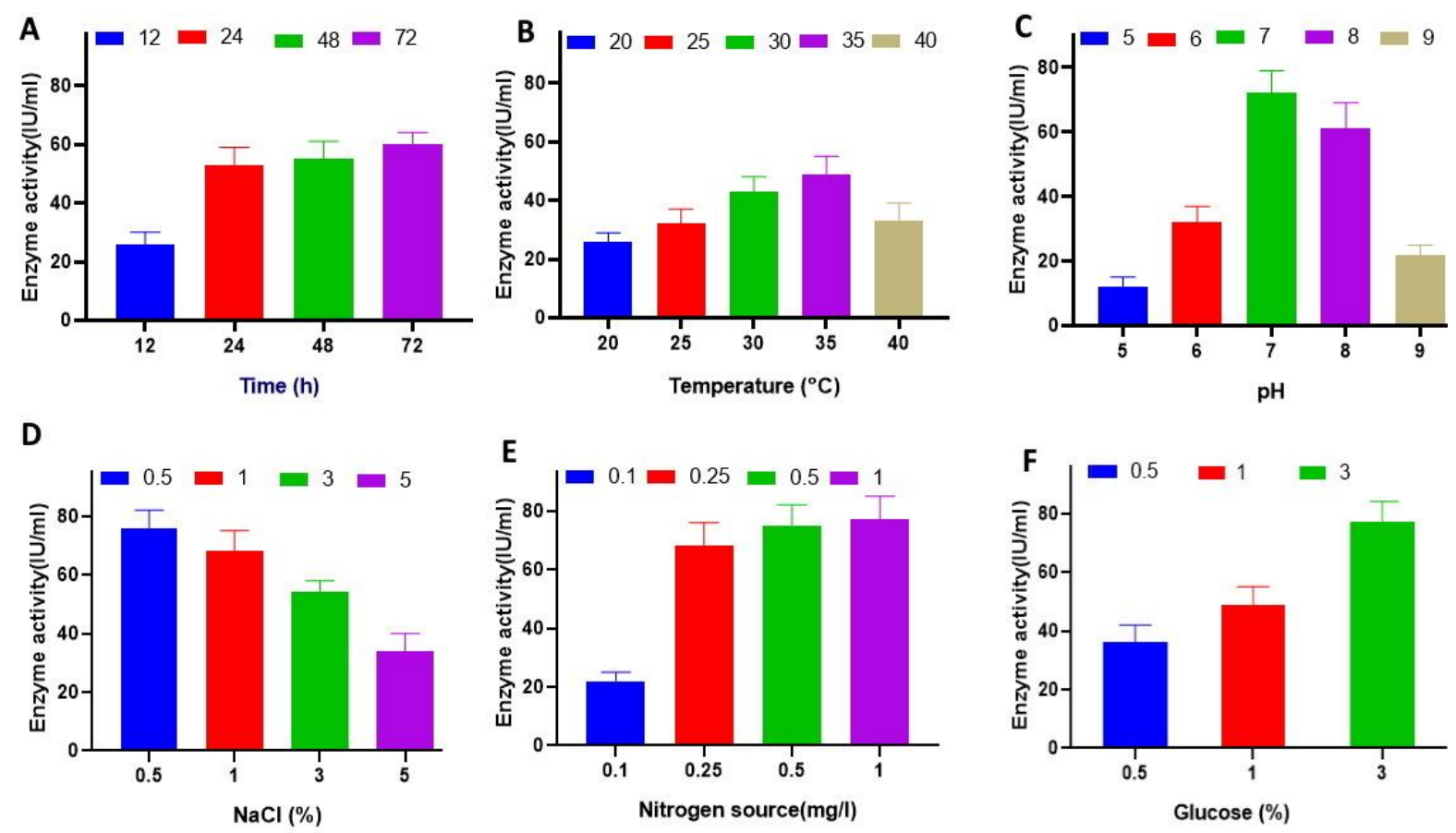

Figure 5. The results of OFAT experiments. Six factors affecting L-Asp activity were analyzed in the different levels, and the significant items were considered for the RSM study.

\subsection{Optimization based on RSM (CCD).}

In accordance with the surface response analysis method calculated on the $\mathrm{CDD}$, four effective factors were investigated to optimize the production of L-ASPase by the bacterium. The results obtained from 30 experiments proposed by the CCD based on the following regression equation:

$$
\begin{gathered}
Y=-1096.68+32.14 X_{2}+37.62 X_{3}+16.50 X_{4}-0.37 X_{1} X_{2}-0.27 X_{2} X_{3}+1.10 X_{2} X_{4}-11.68 X_{1}^{2}- \\
0.50 X_{2}^{2}-8.68 X_{3}^{2}-9.93 X_{4}{ }^{2}
\end{gathered}
$$

The relationship between variables on L-ASPase activity was analyzed based on annotated ANOVA by DOE software to predict the effects of each variable alone and their 
interactive mode. As seen in Table 2, the proposed quadratic model was significant that predicts the responses based on a second-order polynomial equation. Regression analysis around the polynomial model showed the significance of factors $\mathrm{B}, \mathrm{C}, \mathrm{D}, \mathrm{AB}, \mathrm{BC}, \mathrm{BD}, \mathrm{A} 2, \mathrm{~B} 2, \mathrm{C} 2$, and $\mathrm{D} 2$ in the distance of $5 \%$ (P-value <0.05). The meaning of the interactive terms $\mathrm{AB}, \mathrm{BC}$, and $\mathrm{BD}$ means that the interactive effects of $\mathrm{pH}$ on temperature, the temperature on $\mathrm{NaCl}$, and temperature on glucose may affect L-ASPase activity. In addition, the non-significance of lack of fit (LOF) ( $\mathrm{P}>0.05)$ means that the predicted results are consistent with the model [22]. The precision of predicting outcomes based on the present model is accomplished by measuring the difference between the adjusted R-square and the predicted R-square. Based on this, less variance implies a more accurate prediction and more consistent model-calculated performance $[22,34]$. In comparison, the Adeq value of 46.139 shows the high accuracy of the results, which, according to the 4-precision model, describes the adequate accuracy of the measurement (Ad-P>4).

Table 2. Statistical analysis based on annotated ANOVA for L-ASPase activity by Brevibacterium sp. M-R21.

\begin{tabular}{|c|c|c|c|c|c|c|}
\hline Source & Terms & & $p$-value & Source & Terms & p-value \\
\hline Model & quadratic & & $<0.0001 *$ & $\mathrm{BC}$ & Interactive & 0.0143 \\
\hline $\mathrm{pH}(\mathrm{A})$ & Linear & & 0.8398 & BD & Interactive & $<0.0001 *$ \\
\hline Temperature(B) & Linear & & $<0.0001 *$ & $\mathrm{CD}$ & Interactive & 0.3296 \\
\hline $\mathrm{NaCl}(\mathrm{C})$ & Linear & & $0.0006^{*}$ & $\mathrm{~A} 2$ & Squared & $<0.0001^{*}$ \\
\hline Glucose (D) & Linear & & $<0.0001 *$ & $\mathrm{~B} 2$ & squared & $<0.0001 *$ \\
\hline $\mathrm{AB}$ & Interactive & & 0.0018 & $\mathrm{C} 2$ & Squared & $<0.0001 *$ \\
\hline $\mathrm{AC}$ & Interactive & & 0.4615 & D2 & squared & $<0.0001 *$ \\
\hline $\mathrm{AD}$ & Interactive & & 0.6217 & $\begin{array}{l}\text { LOF } \\
\end{array}$ & - & 0.0759 \\
\hline \multicolumn{2}{|l|}{ Parameter } & Value & & Parameter & & Value \\
\hline \multicolumn{2}{|l|}{ Std. Dev. } & 0.020 & & \multicolumn{2}{|c|}{ R-Squared } & 0.9958 \\
\hline \multicolumn{2}{|l|}{ Mean } & 0.34 & & \multicolumn{2}{|c|}{ Adj R-Squared } & 0.9918 \\
\hline \multicolumn{2}{|l|}{ C.V. \% } & 5.88 & & \multicolumn{2}{|c|}{ Pred R-Squared } & 0.9777 \\
\hline \multicolumn{2}{|l|}{ PRESS } & 0.031 & & \multicolumn{2}{|c|}{ Adeq Precision } & 46.139 \\
\hline
\end{tabular}

Table 3. Optimization of L-ASPase activity using RSM based on CCD by Brevibacterium sp. M-R21.

\begin{tabular}{l|c|c|c|c|c|c} 
Run & $\mathbf{p H}(\mathbf{A})$ & $\begin{array}{c}\text { Temperature }(\mathbf{B}) \\
\left({ }^{\circ} \mathbf{C}\right)\end{array}$ & $\begin{array}{c}\mathbf{N a C l}(\mathbf{C}) \\
(\boldsymbol{\%})\end{array}$ & $\begin{array}{c}\text { Glucose }(\mathbf{D}) \\
(\boldsymbol{\%})\end{array}$ & $\begin{array}{c}\text { Predicted } \\
(\mathbf{I U} / \mathbf{m l})\end{array}$ & $\begin{array}{c}\text { Actual } \\
(\mathbf{I U} / \mathbf{m l})\end{array}$ \\
\hline 1 & 8.00 & 25.00 & 1.00 & 3.00 & 50.72 & 48.32 \\
\hline 2 & 6.00 & 25.00 & 1.00 & 3.00 & 47.16 & 45.41 \\
\hline 3 & 8.00 & 35.00 & 1.00 & 1.00 & 31.99 & 32.19 \\
\hline 4 & 7.00 & 30.00 & 2.00 & 0.00 & 23.61 & $24.06^{*}$ \\
\hline 5 & 6.00 & 35.00 & 1.00 & 1.00 & 37.21 & 35.12 \\
\hline 6 & 6.00 & 25.00 & 3.00 & 1.00 & 32.21 & 31.42 \\
\hline 7 & 7.00 & 20.00 & 2.00 & 2.00 & 30.40 & 33.11 \\
\hline 8 & 8.00 & 35.00 & 3.00 & 1.00 & 25.53 & 27.15 \\
\hline 9 & 7.00 & 30.00 & 2.00 & 2.00 & 88.26 & 88.08 \\
\hline 10 & 8.00 & 25.00 & 3.00 & 1.00 & 35.96 & 34.38 \\
\hline 11 & 8.00 & 25.00 & 3.00 & 3.00 & 51.58 & 53.54 \\
\hline 12 & 7.00 & 30.00 & 2.00 & 2.00 & 88.26 & 87.04 \\
\hline 13 & 6.00 & 35.00 & 3.00 & 1.00 & 29.41 & 31.81 \\
\hline 14 & 6.00 & 25.00 & 1.00 & 1.00 & 34.49 & 34.21 \\
\hline 15 & 7.00 & 30.00 & 4.00 & 2.00 & 50.53 & 48.43 \\
\hline 16 & 6.00 & 35.00 & 1.00 & 3.00 & 71.82 & 73.40 \\
\hline 18 & 8.00 & 25.00 & 1.00 & 1.00 & 36.90 & 36.38 \\
\hline 19 & 7.00 & 40.00 & 2.00 & 2.00 & 44.64 & 42.06 \\
\hline 20 & 7.00 & 30.00 & 2.00 & 2.00 & 88.26 & 88.12 \\
\hline 21 & 5.00 & 30.00 & 2.00 & 2.00 & 42.00 & 42.31 \\
\hline 22 & 7.00 & 35.00 & 1.00 & 3.00 & 67.75 & 68.40 \\
\hline 23 & 9.00 & 30.00 & 2.00 & 4.00 & 73.83 & 73.51 \\
\hline 24 & 7.00 & 30.00 & 2.00 & 2.00 & 41.68 & 41.5 \\
\hline 25 & 6.00 & 30.00 & 0.00 & 2.00 & 57.47 & 59.71 \\
\hline 26 & 8.00 & 35.00 & 3.00 & 3.00 & 65.82 & 66.21 \\
\hline 27 & 7.00 & 30.00 & 3.00 & 3.00 & 63.09 & 63.37 \\
\hline 28 & 6.00 & 25.00 & 3.00 & 3.00 & 46.67 & 46.47 \\
\hline
\end{tabular}




\begin{tabular}{l|c|c|c|c|c|c} 
Run & $\mathbf{p H}(\mathbf{A})$ & $\begin{array}{c}\text { Temperature (B) } \\
\left({ }^{\circ} \mathbf{C}\right)\end{array}$ & $\begin{array}{c}\mathbf{N a C l}(\mathbf{C}) \\
(\boldsymbol{\%})\end{array}$ & $\begin{array}{c}\text { Glucose (D) } \\
(\boldsymbol{\%})\end{array}$ & $\begin{array}{c}\text { Predicted } \\
(\mathbf{I U} / \mathbf{m l})\end{array}$ & $\begin{array}{c}\text { Actual } \\
(\mathbf{I U} / \mathbf{m l})\end{array}$ \\
\hline 29 & 7.00 & 30.00 & 2.00 & 2.00 & 88.26 & $90.11^{* *}$ \\
\hline 30 & 7.00 & 30.00 & 2.00 & 2.00 & 88.26 & 89.16
\end{tabular}

All responses associated with run orders have presented in Table 2. As can be seen, the lowest and highest responses were determined to run order 4 and 29 that were 24.06 and 90.11 $\mathrm{IU} / \mathrm{ml}$, respectively.

Three-dimensional plots (3D) represent the significant interaction of independent variable pairs (Figure 6). These plots provide a better understanding of the polynomial model in the interactive situation between independent factors. The highlights are determined based on the interactive powers of each of the independent variables [22].
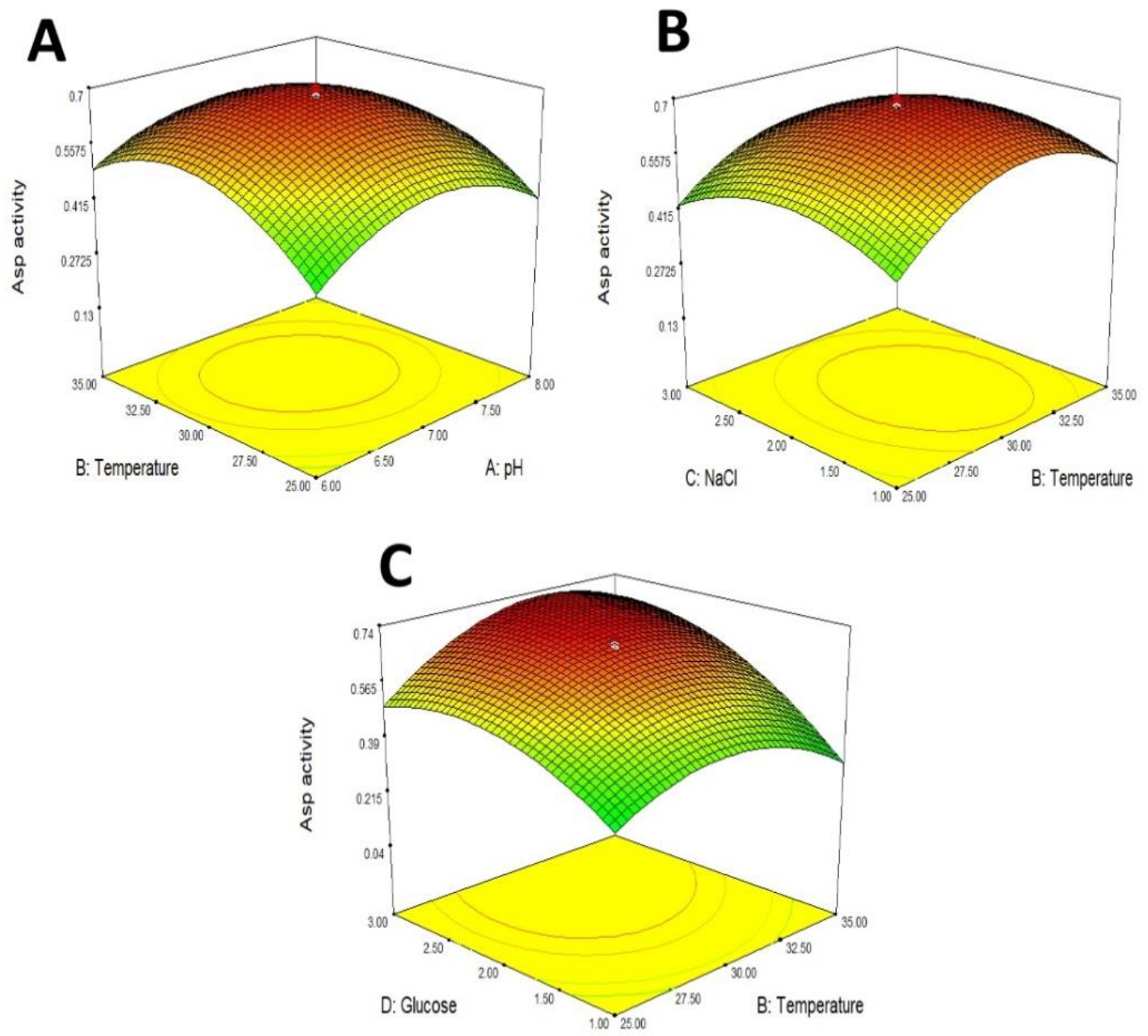

Figure 6. 3D plots show interactive effects between variables: A) temperature and $\mathrm{pH}$ with a polynomial curvature; (b) $\mathrm{NaCl}$ and temperature with polynomial (c) glucose and temperature with significant polynomial and curvature.

In the present study, the specific activity was obtained in optimal condition about 90 $\mathrm{IU} / \mathrm{mg}$, which was similar to commercial L-ASPase produced by E. coli reported with about $85 \mathrm{IU} / \mathrm{mg}$. These increased activities were related to the central points, including $\mathrm{pH} 7$, temperature $30{ }^{\circ} \mathrm{C}, \mathrm{NaCl} 2 \%$, and glucose $2 \%$. The lowest activity of L-ASPase was obtained at $\mathrm{pH} 7$, temperature, $30{ }^{\circ} \mathrm{C}, \mathrm{NaCl}, 2 \%$, lacking any carbon source, i.e., glucose. This was higher than the value reported by Dias et al. (2016), who obtained $67.49 \mathrm{U} \mathrm{mL} 1$ for L-ASPase activity from Aspergillus oryzae CCT 3940 after optimization of process conditions [34]. 
Optimization for the L-ASPase production by the OFAT method revealed that the incubation time and nitrogen source had no significant effects on bacterial L-ASPase activity. However, L-ASPase activity increased significantly with changes in $\mathrm{pH}$. This trend was also confirmed in the statistical optimization method, where the highest L-ASPase activity occurred in neutral $\mathrm{pH}$. Besides, the temperature affecting the L-ASPase production was $30^{\circ} \mathrm{C}$, although L-ASPase activity remained high in the temperature range of 30 to $40{ }^{\circ} \mathrm{C}$. In our previous report, Rouxiella sp. AF1 isolated from farmland soils had the best L-ASPase activity at $30{ }^{\circ} \mathrm{C}$, $\mathrm{pH} 7, \mathrm{NaCl} 3 \%$, and glucose 1\% [21]. Some reports have claimed that many Bacillus genus members showed L-ASPase activity in the $\mathrm{pH}$ range of 6-8 and temperature $37{ }^{\circ} \mathrm{C}[26,27,35]$. Significant reductions in L-ASPase activity at low $\mathrm{pH}$ may be attributed to change in enzyme affinity to the substrate [36].

\section{Conclusions}

Due to the relatively favorable anti-tumor activity of L-ASPase produced by Brevibacterium sp. M-R21 could potentially be used for pharmaceutical use as well as in the food industry to remove acrylamide. In addition, optimization experiments with a combination of OFAT and a central composite design provided a reliable approach for evaluating enzyme production. Although Extraction and purification of L-Asp yielded low enzyme by ammonium sulfate precipitation, dialysis, and then column chromatography, its purity showed to be significantly satisfactory. Taken together, this study showed that the use of endophytes isolated from medicinal plants could be a good alternative to find new metabolites, especially L-Asp, for pharmaceutical applications.

\section{Funding}

This research was funded by Lorestan University of Medical Sciences, grant number "IR.LUMS.REC.1397.154".

\section{Acknowledgments}

This research was performed in Razi Herbal Medicines Research Center, Lorestan University of Medical Sciences.

\section{Conflicts of Interest}

The authors declare no conflict of interest.

\section{References}

1. Borges GÁ, Elias ST, Araujo TS, Souza PM, Nascimento-Filho CH, Castilho RM, Squarize CH, Magalhães PD, Guerra EN. Asparaginase induces selective dose-and time-dependent cytotoxicity, apoptosis, and reduction of NFKB expression in oral cancer cells. Clinical and Experimental Pharmacology and Physiology 2020, 47, 857-866, https://doi.org/10.1111/1440-1681.13256

2. Saeed, H.; Hemida, A.; El-Nikhely, N.; Abdel-Fattah, M.; Shalaby, M.; Hussein, A.; Eldoksh, A.; Ataya, F.; Aly, N.; Labrou, N.; Nematalla, H. Highly efficient Pyrococcus furiosus recombinant L-asparaginase with no glutaminase activity: Expression, purification, functional characterization, and cytotoxicity on THP-1, A549 and Caco-2 cell lines. International Journal of Biological Macromolecules 2020, 156, 812-828, https://doi.org/10.1016/j.ijbiomac.2020.04.080.

3. Shakambari, G.; Ashokkumar, B.; Varalakshmi, P. L-asparaginase-A promising biocatalyst for industrial and clinical applications. Biocatalysis Agricultural Biotechnology 2019, 17, 213-224. https://doi.org/10.1016/j.bcab.2018.11.018. 
4. Ghorbanmovahed, M.; Ebrahimipour, G.; Akhtari, J.; Marzban, A. Production of anti-leukemia LAsparaginase by a strain of Staphylococcus Isolated from Agricultural Soil. Journal of Mazandaran University of Medical Sciences 2016, 25, 1-12.

5. Chiu, M.; Taurino, G.; Bianchi, M.G.; Kilberg, M.S.; Bussolati, O. Asparagine Synthetase in Cancer: Beyond Acute Lymphoblastic Leukemia. Frontiers in Oncology 2019, 9, https://doi.org/10.3389/fonc.2019.01480.

6. Sharma D, Singh K, Singh K, Mishra A. Insights into the Microbial L-Asparaginases: from Production to Practical Applications. Current Protein and Peptide Science 2019, 20, 452-464, https://doi.org/10.2174/1389203720666181114111035.

7. Lubkowski, J.; Vanegas, J.M.; Chan, W.-K.; Lorenzi, P.L.; Weinstein, J.N.; Sukharev, S.; Fushman, D.; Rempe, S.; Anishkin, A.; Wlodawer, A. The mechanism of catalysis by L-asparaginase. Biochemistry Supplement Series B: Biomedical Chemistry 2020, 59, 1927-1945, https://doi.org/10.1021/acs.biochem.0c00116.

8. Zuo, W.; Deng, M.; Yin, Q.; Jianwei, D.; Zhu, X. Clinical efficacy and safety of L-asparaginase combined with GDP regimen in treat-ment of patients with extranodal NK/T-cell lymphoma. Chinese Journal of Clinical Oncology 2017, 44, 321-323.

9. Ghorbanmovahed, M.; Ebrahimipour, G.; Marzban, A. Inhibitory and Stimulatory Effects of Some Metals on Asparaginase Activity Produced by Staphylococcus MGM1. Iranian Journal of Medical Microbiology 2019, 13, 374-379, https://doi.org/10.30699/ijmm.13.5.374.

10. Khalil, M.S.; Moubasher, M.H.; Mokhtar, M.; Michel, M.M. Evaluation of antitumor activity of fungal Lglutaminase produced by egyptian isolates. Letters in Applied NanoBioScience 2020, 9, 924-930, https://doi.org/10.33263/LIANBS91.924930.

11. Vala, A.K.; Sachaniya, B.; Dudhagara, D.; Panseriya, H.Z.; Gosai, H.; Rawal, R.; Dave, B.P. Characterization of L-asparaginase from marine-derived Aspergillus niger AKV-MKBU, its antiproliferative activity and bench scale production using industrial waste. International journal of biological macromolecules 2018, 108, 41-46, https://doi.org/10.1016/j.ijbiomac.2017.11.114.

12. Shrivastava, A.; Khan, A.A.; Khurshid, M.; Kalam, M.A.; Jain, S.K.; Singhal, P.K. Recent developments in 1-asparaginase discovery and its potential as anti-cancer agent. Critical Reviews in Oncology/Hematology 2016, 100, 1-10, https://doi.org/10.1016/j.critrevonc.2015.01.002.

13. Muneer, F.; Siddique, M.H.; Azeem, F.; Rasul, I.; Muzammil, S.; Zubair, M.; Afzal, M.; Nadeem, H. Microbial L-asparaginase: purification, characterization and applications. Archives of Microbiology 2020, 1-15. https://doi.org/10.1007/s00203-020-01814-1

14. Krishnapura, P.R.; Belur, P.D. Isolation and screening of endophytes from the rhizomes of some Zingiberaceae plants for L-asparaginase production. Preparative Biochemistry \& Biotechnology 2016, 46, 281-287, https://doi.org/10.1080/10826068.2015.1031385.

15. Arora, P.; Wani, Z.A.; Nalli, Y.; Ali, A.; Riyaz-Ul-Hassan, S. Antimicrobial Potential of Thiodiketopiperazine Derivatives Produced by Phoma sp.; an Endophyte of Glycyrrhiza glabra Linn. Microbial Ecology 2016, 72, 802-812, https://doi.org/10.1007/s00248-016-0805-X.

16. Selyutina OY, Polyakov NE. Glycyrrhizic acid as a multifunctional drug carrier-From physicochemical properties to biomedical applications: A modern insight on the ancient drug. International Journal of Pharmaceutics 2019, 559, 271-279, https://doi.org/10.1016/j.ijpharm.2019.01.047.

17. Nedil'Ko, O.V.; Yanitskaya, A.V. The study of amino acid content of Glycyrrhiza glabra over-ground and underground parts. Chemistry of Plant Raw Material 2020, 1, 251-256, https://doi.org/10.14258/jcprm.2020014678.

18. AL-zebari PJ, Sarhan TZ. Effect of Licorice Root Extract and Humic Acid on Yield Characters of Summer Squash (Cucurbita pepoL.). Journal of Duhok University 2019, 22, 960, https://doi.org/10.26682/ajuod.2019.22.2.5.

19. Marzban, A.; Ebrahimipour, G.; Karkhane, M.; Teymouri, M. Metal resistant and phosphate solubilizing bacterium improves maize (Zea mays) growth and mitigates metal accumulation in plant. Biocatalysis and Agricultural Biotechnology 2016, 8, 13-17, https://doi.org/10.1016/j.bcab.2016.07.005.

20. Ebrahimipour, G.; Moradi, A.; Mehrdad, M.; Marzban, A.; Alaee, H. Evaluation of antimicrobial substance produced by a bacterium isolated from Parmacella iberica. Jundishapur Journal of Microbiology 2011, 4, 131-141.

21. Gilavand, F.; Kavyanifard, A.; Marzban, A. L-Asparaginase-producing Rouxiella Species Isolation, Antileukemia Activity Evaluation, and Enzyme Production Optimization. Research in Molecular Medicine 2018, 6, 29-44, https://doi.org/10.18502/rmm.v6i3.4608.

22. Teymouri, M.; Karkhane, M.; Gilavand, F.; Akhtari, J.; Marzban, A. Extracellular Lipase Purification from a Marine Planomicrobium sp. MR23K and Productivity Optimization in a Pilot-Scale Submerged Bioreactor. Proceedings of the National Academy of Sciences, India Section B: Biological Sciences 2018, 88, 739-746, https://doi.org/10.1007/s40011-016-0812-1.

23. Andriiash GS, Sekan OS, Tigunova OO, Blume YB, Shulga SM. Metabolic Engineering of Lysine Producing Corynebacterium glutamicum Strains. Cytology and Genetics 2020, 54, 137-146, https://doi.org/10.3103/S0095452720020024. 
24. Sudhir, A.P.; Agarwaal, V.V.; Dave, B.R.; Patel, D.H.; Subramanian, R.B. Enhanced catalysis of 1asparaginase from Bacillus licheniformis by a rational redesign. Enzyme and Microbial Technology 2016, 86, 1-6, https://doi.org/10.1016/j.enzmictec.2015.11.010.

25. Zhang, S.; Xie, Y.; Zhang, C.; Bie, X.; Zhao, H.; Lu, F.; Lu, Z. Biochemical characterization of a novel 1asparaginase from Bacillus megaterium $\mathrm{H}-1$ and its application in French fries. Food Research International 2015, 77, 527-533, https://doi.org/10.1016/j.foodres.2015.08.031.

26. Lu X, Chen J, Jiao L, Zhong L, Lu Z, Zhang C, Lu F. Improvement of the activity of l-asparaginase I improvement of the catalytic activity of 1-asparaginase I from Bacillus megaterium $\mathrm{H}-1$ by in vitro directed evolution. Journal of Bioscience and Bioengineering 2019, 128, 683-689, https://doi.org/10.1016/j.jbiosc.2019.06.001.

27. Alrumman, S.A.; Mostafa, Y.S.; Al-izran, K.A.; Alfaifi, M.Y.; Taha, T.H.; Elbehairi, S.E. Production and Anticancer Activity of an L-Asparaginase from Bacillus licheniformis Isolated from the Red Sea, Saudi Arabia. Scientific Reports 2019, 9, https://doi.org/10.1038/s41598-019-40512-x.

28. Roy, M.P.; Das, V.; Patra, A. Isolation, purification and characterization of an extracellular L-asparaginase produced by a newly isolated Bacillus megaterium strain MG1 from the water bodies of Moraghat forest, Jalpaiguri, India. The Journal of General Applied Microbiology 2018, 65, 137-144, https://doi.org/10.2323/jgam.2018.07.004.

29. Moharib, S.A. Anticancer activity of L-asparaginase produced from Vigna unguiculata. World Scientific Research 2018, 5, 1-12, https://doi.org/10.20448/journal.510.2018.51.1.12.

30. Sudarkodi, C.; Sundar, S.J.I.J.R.S.R. Anticancer activity of L-asparaginase from Aspergillus oryzae against HEP-G2 and Hela cell lines. International Journal of Recent Scientific Research 2018, 9, 25328-25330.

31. Rani, S.A.; Sundaram, L.; Vasantha, B. In vitro antioxidant and anti-cancer activity of L-asparaginase from Aspergillus flavus (KUFS20). Asian Journal of Pharmaceutical and Clinical Research 2011, 4, 174-177.

32. Srikhanta, Y.N.; Atack, J.M.; Beacham, I.R.; Jennings, M.P. Distinct physiological roles for the two Lasparaginase isozymes of Escherichia coli. Biochemical Biophysical Research Communications 2013, 436, 362-365, https://doi.org/10.1016/j.bbrc.2013.05.066.

33. Teymouri, M.; Karkhane, M.; Marzban, M.; Marzban, A. Designing a Response Surface Model for Removing Phosphate and Organic Compound from Wastewater by Pseudomonas Strain MT1. Proceedings of the National Academy of Sciences, India Section B: Biological Sciences 2017, 87, 1167-1176, https://doi.org/10.1007/s40011-015-0686-7.

34. Dias, F.F.; Sato, H.H. Sequential optimization strategy for maximum 1-asparaginase production from Aspergillus oryzae CCT 3940. Biocatalysis and Agricultural Biotechnology 2016, 6, 33-39, https://doi.org/10.1016/j.bcab.2016.02.006.

35. Moorthy, V.; Ramalingam, A.; Sumantha, A.; Shankaranaya, R.T. Production, purification and characterisation of extracellular L-asparaginase from a soil isolate of Bacillus sp. African Journal of Microbiology Research 2010, 4, 1862-1867.

36. Meena, B.; Anburajan, L.; Dheenan, P.S.; Begum, M.; Vinithkumar, N.V.; Dharani, G.; Kirubagaran, R. Novel glutaminase free L-asparaginase from Nocardiopsis alba NIOT-VKMA08: production, optimization, functional and molecular characterization. Bioprocess Biosystems Engineering 2015, 38, 373-388, https://doi.org/10.1007/s00449-014-1277-3. 